\title{
DEVELOPING AUGMENTED REALITY APP FOR SMART PACKAGING
}

\author{
Stefan Đurđević ${ }^{1}$ (D), Dragoljub Novaković ${ }^{1}$ (D), Savka Adamović ${ }^{1}$ (D), \\ Frank Boadu ${ }^{2}$, Adriana Rodríguez Lezaca ${ }^{3}$, Željko Zeljković ${ }^{1}$ \\ ${ }^{1}$ University of Novi Sad, Faculty of Technical Sciences, \\ Department of Graphic Engineering and Design, Novi Sad, Serbia \\ ${ }^{2}$ University Printing Press, Kwame Nkrumah University \\ of Science and Technology (KNUST), Kumasi, Ghana \\ ${ }^{3}$ SENA, National Training Service, Bogota, Colombia
}

\begin{abstract}
Augmented Reality technology is increasingly present smart packaging feature. This paper presents the development of the smart packaging application that will provide information on the state of the product in packaging using the Augmented reality technology as a result. In order to control the product state, freshness control labels were printed with stimuli-responsive dyes in the form of specific code. These dyes are conceivable for all environmentally sensitive goods during storage and transport such as food, seeds, pharmaceuticals, cosmetics, electronics etc. These dyes are very useful for controlling the product freshness because they do not require an additional power supply and they can be monitored optically via the smart device camera. Stimuli-responsive dyes can report different environmental influences such as water/moisture, temperature, light, pressure, $\mathrm{pH}$, etc. in a one-bit binary state or in gradually changing optical properties. The aim of the paper is the development of the application that will provide product freshness information based on packaging design (product type) and different environmental influences.
\end{abstract}

Key words: augmented reality, product quality, smart packaging, smart labels, stimuli-responsive dyes

\section{INTRODUCTION}

There is a long list of various "smart materials" that enhance smart packages. These include shape memory alloys to control the opening and closing of packages depending on environmental conditions, piezoelectric materials to provide power for lighting and audio features on packaging, smart adhesives that can be used in conjunction with smart labels, thermochromic inks to show when optimal or dangerous temperatures have been reached, etc. (Furht, 2011). There are features and benefits of combining these smart materials with Augmented Reality technology. In this paper, we will describe how to develop the smart labels and augmented reality app for identifying product state. A smart label will be printed with screen printing inks tone sensitive to the change of essential parameters for the preservation of product state (time, temperature, UV rays, humidity, etc.), and the Augmented Reality app will be developed in Swift program language for new iOS 11 devices.

\subsection{Stimuli-responsive dyes}

Stimuli-responsive or sensitive dyes change their absorption spectrum through induced transformations of light, temperature, $\mathrm{pH}$, water, etc. The most-known organic compound in this category is spiropyran; its reversible closure properties are extensively examined. Induced by heating and light irradiation, it becomes coloured (Hunger, 2003).

In recent years stimuli-responsive dyes are used for the printing, packaging, security (brand protection, traceability, tamper-evidence), medical sterilisation, heat and radiation curing, food retorting, coding and marking, etc. (Siltechlimited, 2018).

Smart inks can respond to the following sources of stimulation (Sfxc, 2018):

- Gamma Radiation

- UV Radiation

- Temperature (Heat or cold)

- Steam

- Ethylene Oxide

- Infrared Radiation etc. 
Thermochromic inks or dyes are temperature sensitive (Stančić et al, 2013) compounds that change colour gradually in response to fluctuations in temperatures. There are both irreversible and reversible types (Sfxc, 2018).

\subsection{Smart Labels}

There are different types of smart labels developed for smart packaging. In this paper, we are based on creating Augmented Reality application for the specific thermochromic label. These labels were developed by Đurđević et al. (Đurđević et al, 2017). The labels were printed in the first pass, with thermochromic ink and after drying process in the second pass, labels were printed with conventional ink (Figure 1).

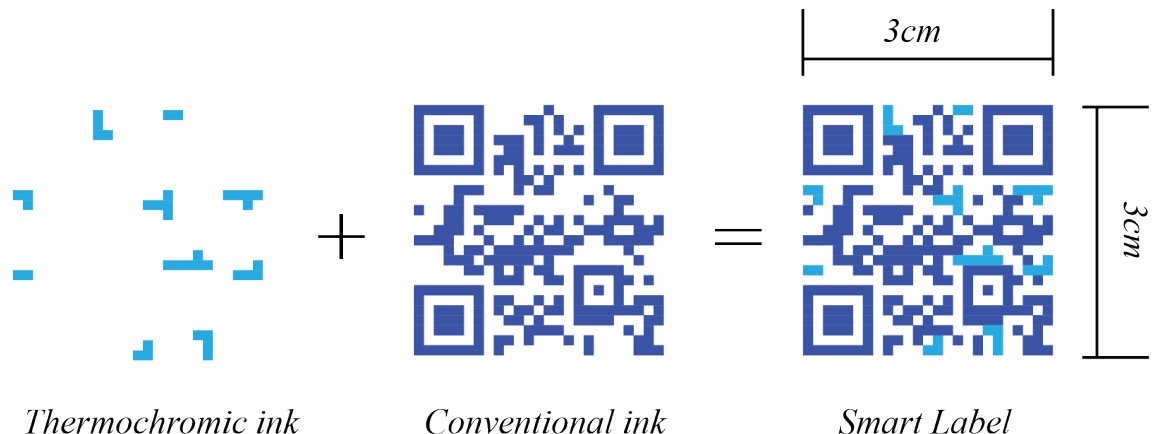

Figure 1: Thermochromic Smart label printing process

\subsection{Smart packaging}

Smart packaging provides enhanced functionality that can be divided into two submarkets: active packaging and intelligent packaging (Packagingdigest, 2018). Active packaging is packaging, which has an extra function in addition to that of providing a protective barrier against external influence. It can control, and even react to, phenomena taking place inside the package. Intelligent packaging monitors to give information on the quality and state of the packed product. Smart, intelligent or clever packaging is defined as a packaging technique containing an external or internal indicator for the active product history and quality (Febech et al, 2000).

\subsection{Augmented Reality Technology}

AR-technology has huge possibilities, and only technology and imagination set the limit on what can be achieved with it. AR-technology can be used in many fields such as commercial, games, navigation, tourism, medicine, military, maintenance, etc. (Azuma, 1997; Sielhorst et al, 2004; Jung et al, 2008; Reitmayr et al, 2004; Platonov et al, 2006). In recent years, a wide variety of AR technologies and applications have been developed (Van Krevelen et al, 2013; Caudell et al, 1992).

The term "Augmented Reality" was coined by Caudell and Mizell (Caudell et al, 1992) in 1992, as superimposing environment whose elements are merged with augmented computer-generated images creating a mixed reality (Furht, 2011). Unlike virtual reality, which creates an artificial environment, Augmented Reality uses the existing environment and overlays new information on top of it. That means Augmented Reality requires less computation resource than Virtual Reality (VR) because it only needs to render the overlaid objects instead of every pixel on the screen.

Augmented Reality combines real and virtual, it is interactive in real time and registered in 3D (Azuma, 1997). Combines real and virtual means that information or animations are displayed on the same screen as the user sees the actual world on or through, to enhance what the user can see and read out from realworld objects. Interactive in real time means that the user can interact with whatever information is displayed in the AR system. For instance, a user might look at a food packaging and is provided information about the food manufacturer and by clicking on this information the user can get the other food product list or the manufacturer's website (Figure 2). Registered in 3D means that virtual information is displayed and aligned with the real-world object (Tholsgard, 2014). 


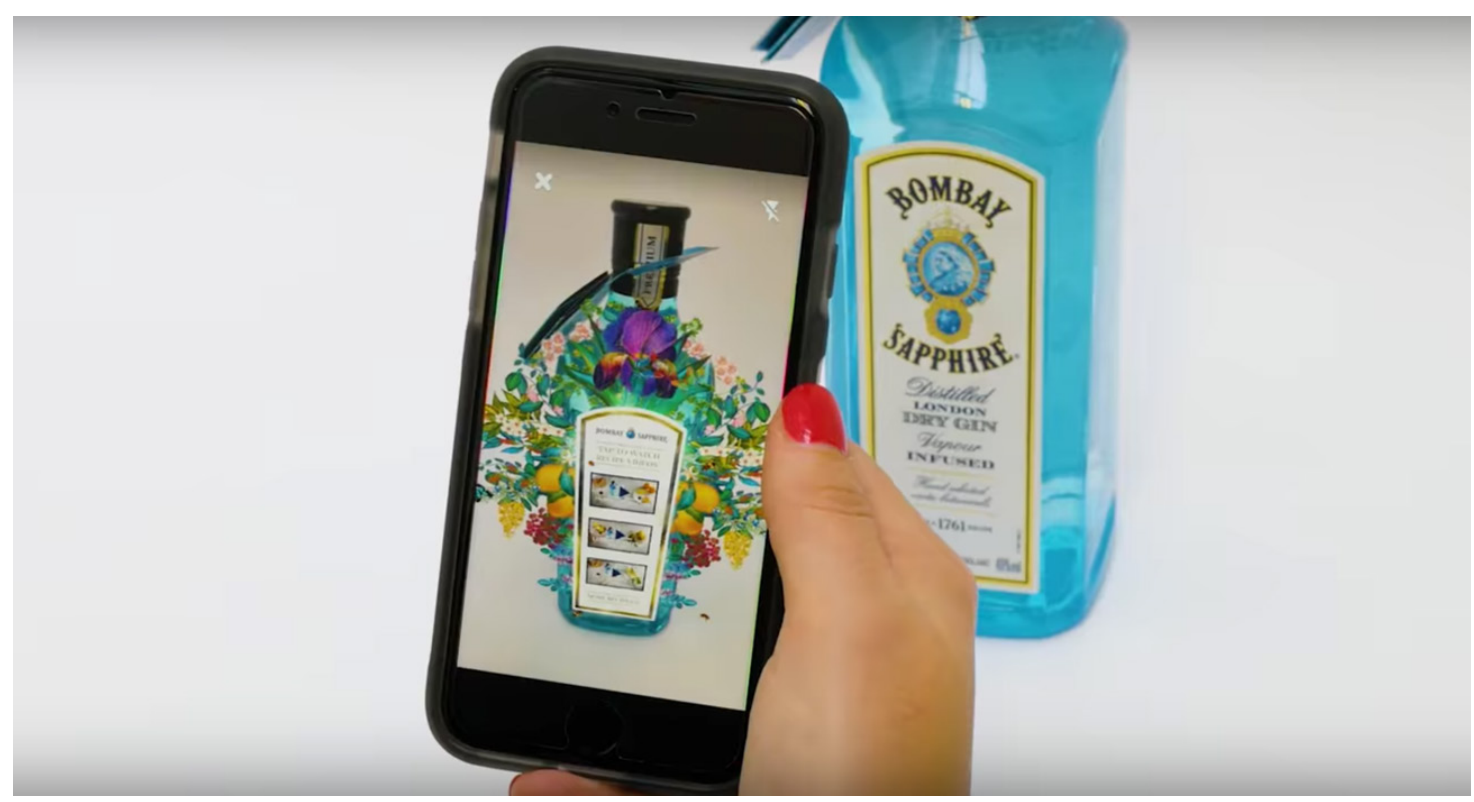

Figure 2: Augmented Reality App activated after product label scan

\subsection{Problem Description}

This work aims to develop the Augmented Reality app that is possible to check the product state via comparing packaging design (product type) and smart thermochromic label. The Smart thermochromic label was the previous research, and its development can be found in Đurđević et al. (Đurđević et al, 2017) article.

\section{METHODS AND TOOLS}

The following applications were used for the Augmented Reality smart packaging application development: 3D Studio Max for 3D modelling of freshness indicator, Xcode 9.4.1 and Swift 4 for programming application for iOS devices, as well as the Adobe Illustrator CC, Adobe Photoshop CC and Sketch for creating design interface of the application.

\section{RESULTS}

The basis of this application is the Smart Label image consisting fields printed with conventional inks and fields printed with irreversible thermochromatic inks that disappear if they reach the higher temperature in the ambient than the activation temperature (for the used type of ink 30oC). Developing code for this type of smart packaging labels is shown in previous research (Đurđević et al, 2017).

Smart labels are applied to existing packaging, where the first target is the segment of packaging design side to applied label, second is the non-activated label code design, and the third is the label code in the activated form. In this way, the device recognises the product and the status of the label code, and by linking this two information gives freshness state of the product. For example, if the frost product is concerned, activating the thermochromatic ink will signal that the product was thawed during storage, and because of that, it is not fresh anymore. Parts of the user interface design were created in vector graphics software from the Adobe CC package, Adobe Illustrator, and integrated into UI design software Sketch (Figure 3). Finally, user interface design from Sketch is used in Xcode. 


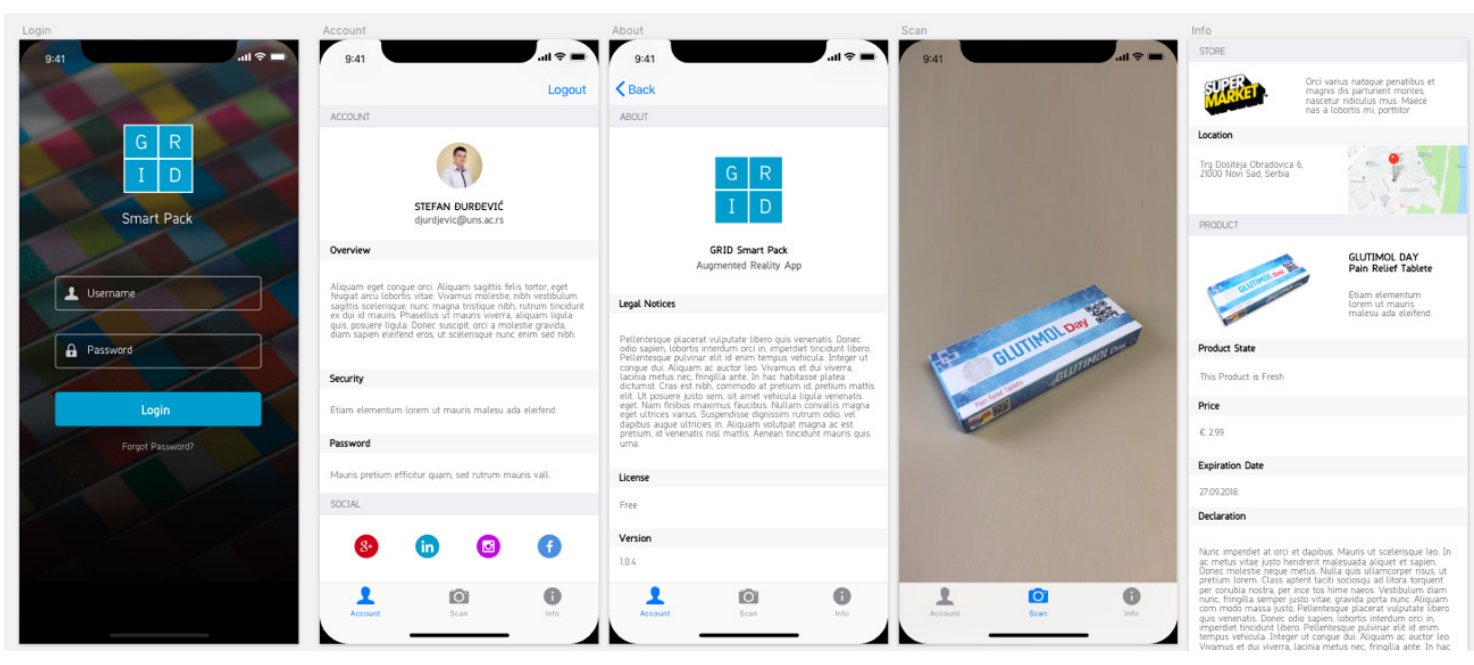

Figure 3: Smart Packaging Application UI development in Sketch

It can be seen that based on the GPS location, additional information about the identified product is also loaded on the interface, such as the price, the declaration, the store, the expiration date. Figure 4 shows View Controllers in Xcode. Application interface screens can be found in figure 3.

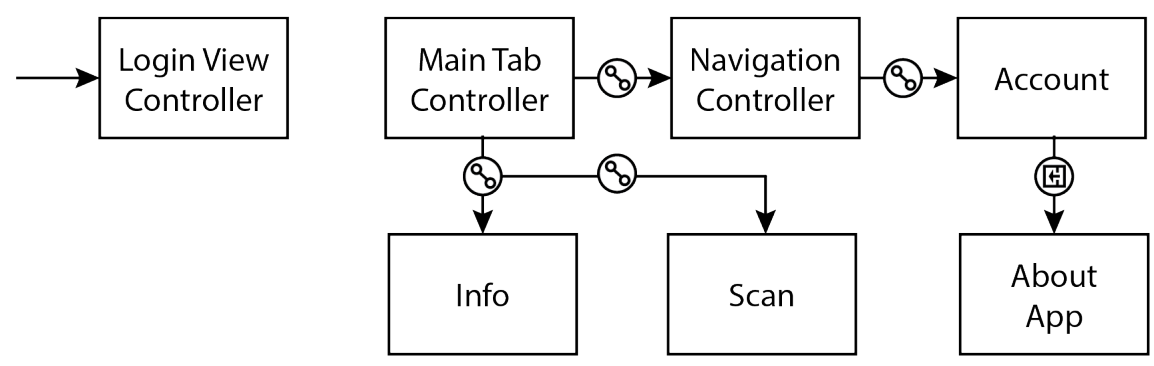

Figure 4: Augmented Reality app View Controllers connections in xCode

The "Scan" tab allows you to launch an AR camera that recognises the product and its freshness and prints data within the "Info" tab. Bzelow is the code that is associated with the View Controller "Scan" tab and "Scan" tab in use while the application is running on a smartphone (Figure 6).

First, it is necessary to import code packages for Augmented Reality and User Interface development.

\author{
import Foundation \\ import UIKit \\ import ARKit
}

Then in this part of code buttons are linked with View Controllers.

\title{
class SecondViewController: UIView Controller \{ \\ @IBOutlet weak var sceneView: ARSCNView! \\ @IBOutlet weak var label: UILabel!
}

This part of the code is responsible for 3D object Fresh animation setup (fade duration, rotation, spin action, etc.).
let fadeDuration: Timelnterval $=0.3$
let rotateDuration: Timelnterval $=10$
let waitDuration: Timelnterval $=0.5$ 


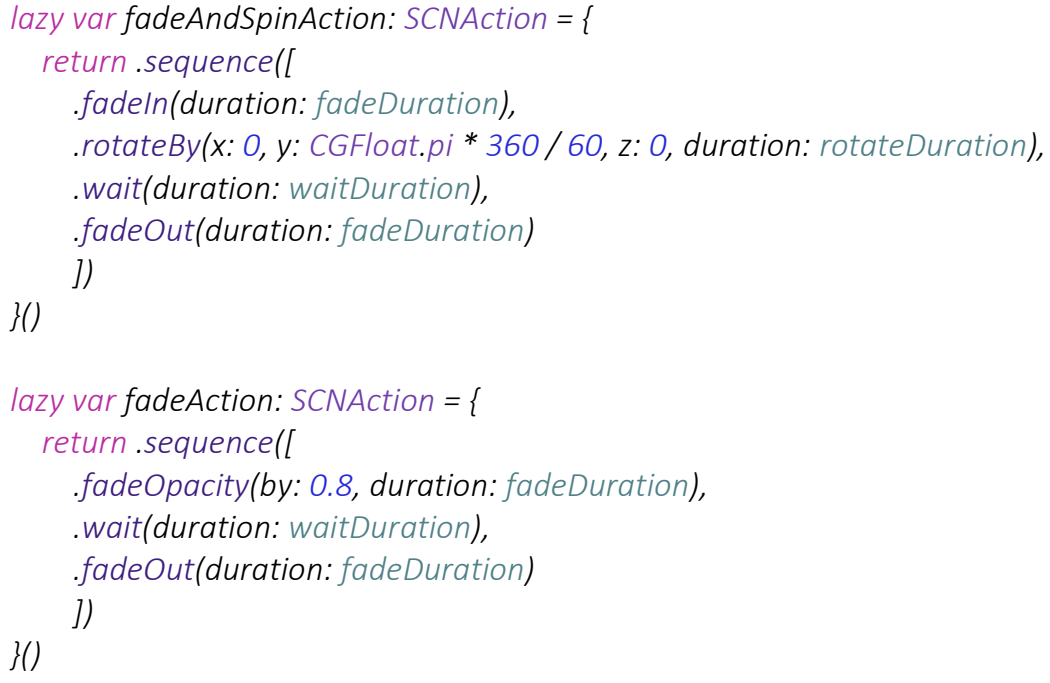

In this part of the code, we can see product state $3 \mathrm{~d}$ models. We can see three product states depending on product type and label state combination (fresh, check again, do not use).

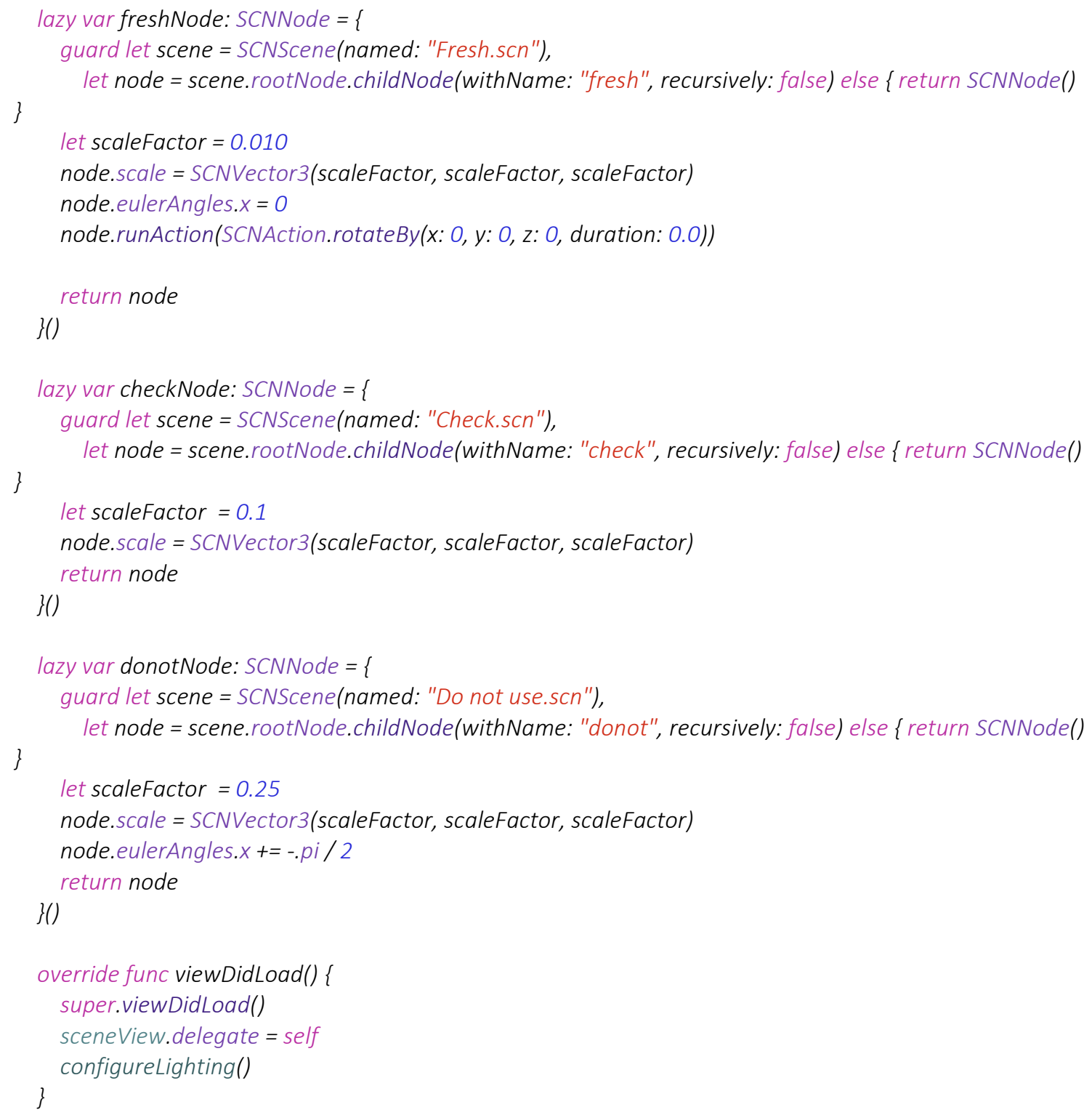




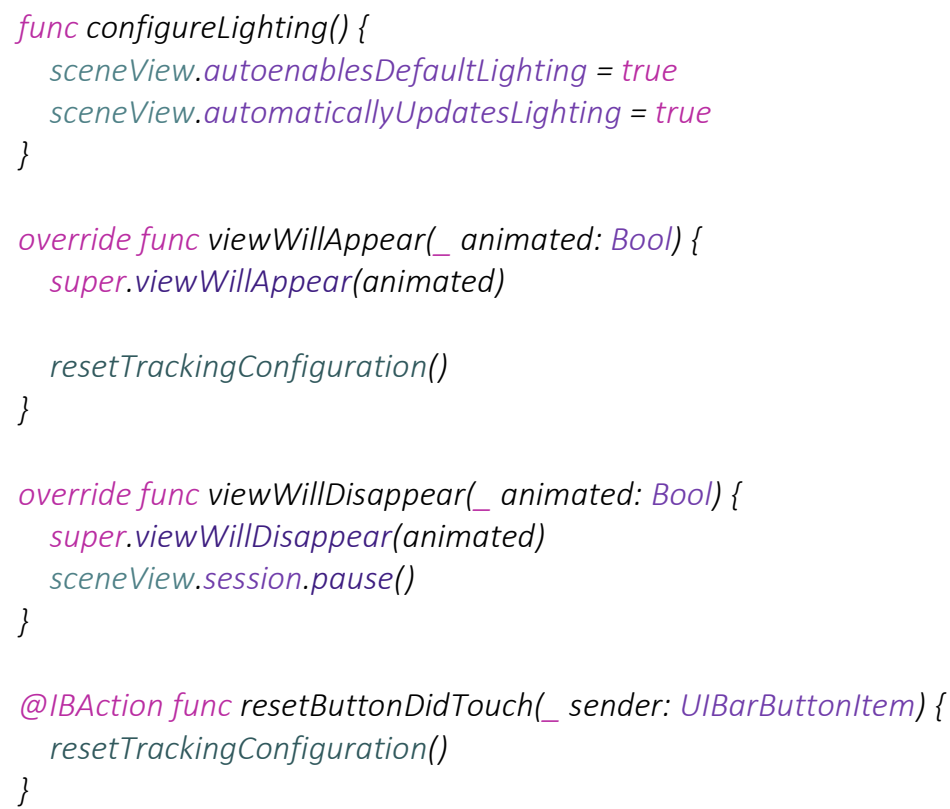

Here is the part of the code to give the information to a user to move the camera to detect smart packaging.

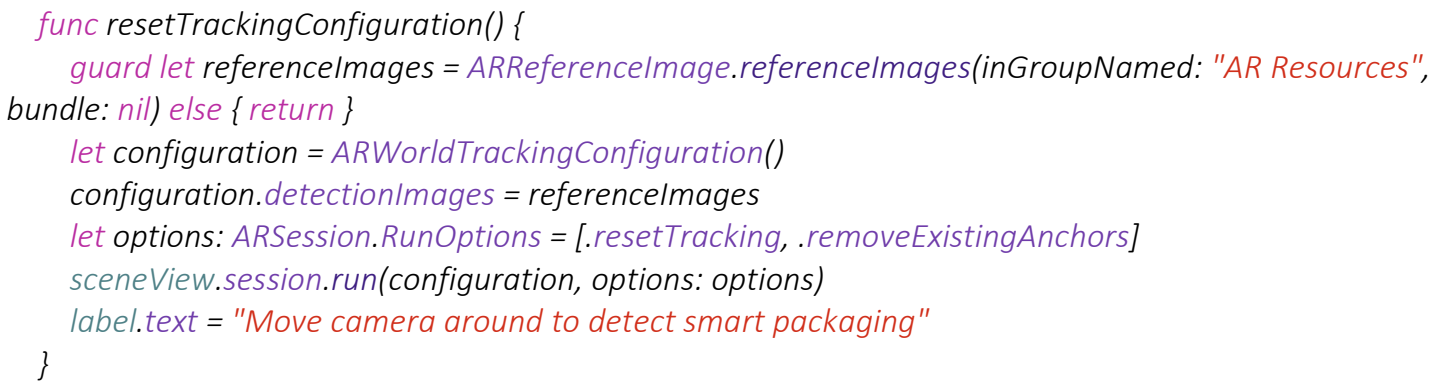

This part of the code will render information about packaging name and state after detection.

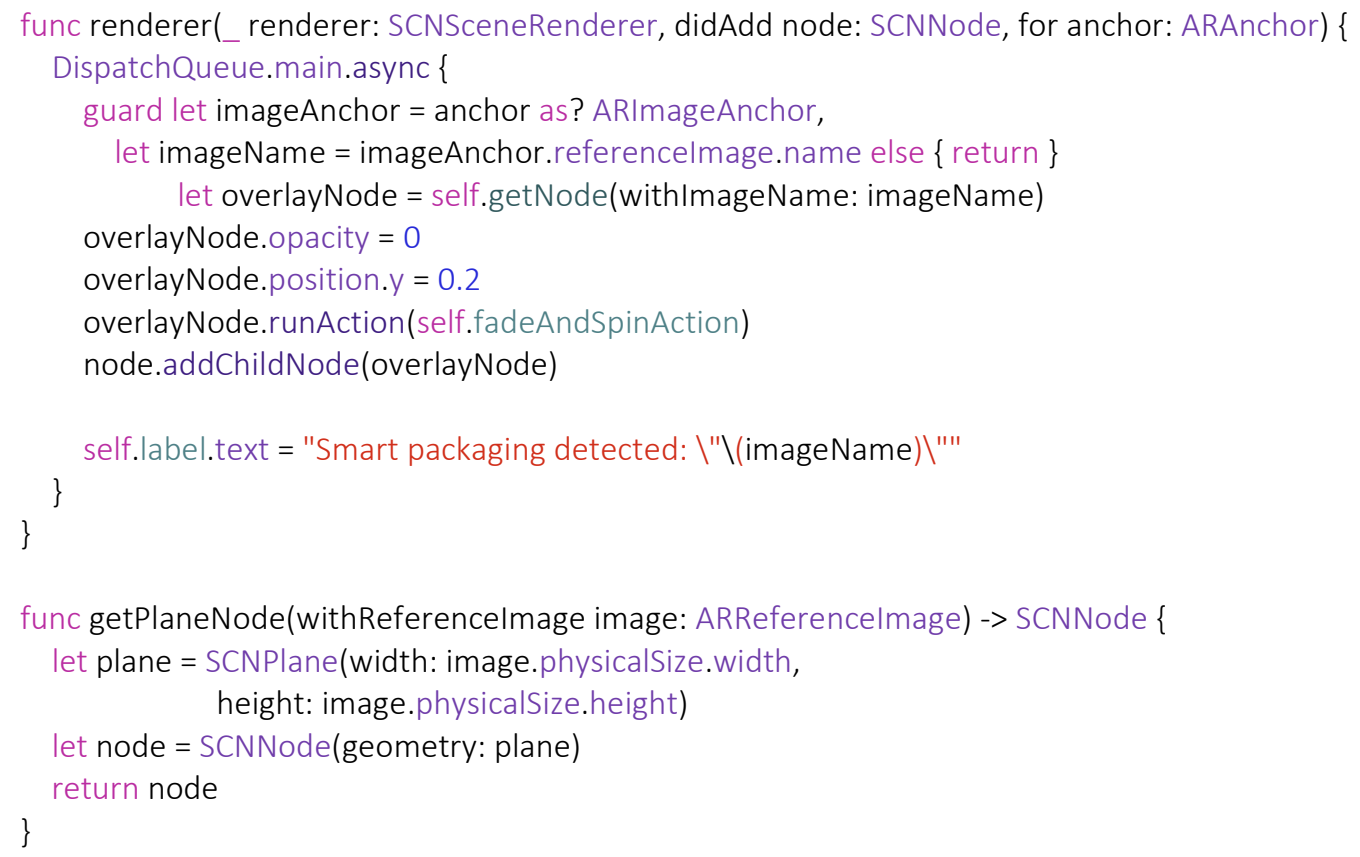




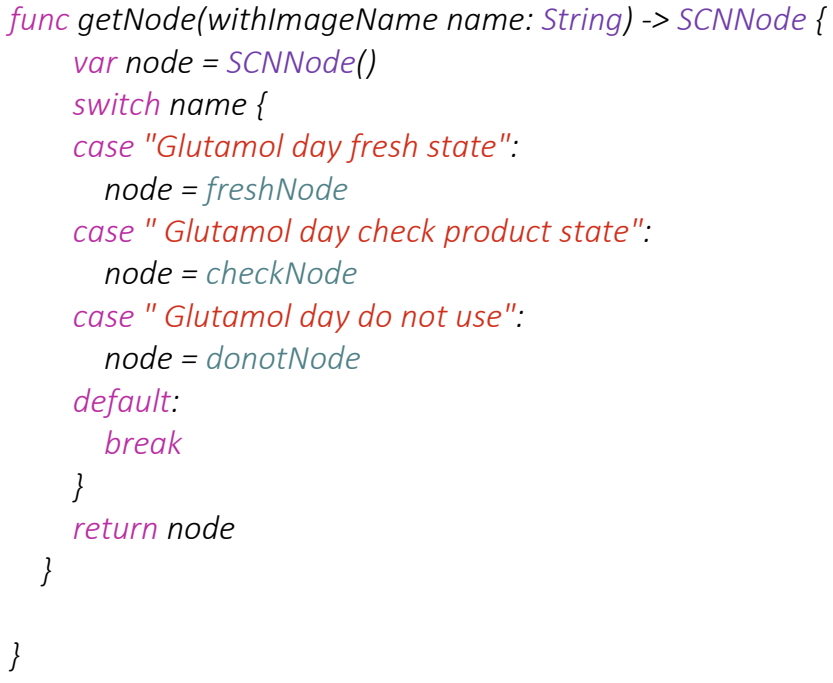

To build the application on a mobile device, Xcode 9.4 and programing language, Swift was used. Figure 5 shows the $x$ Code screen while App is running in test mode on a mobile device.

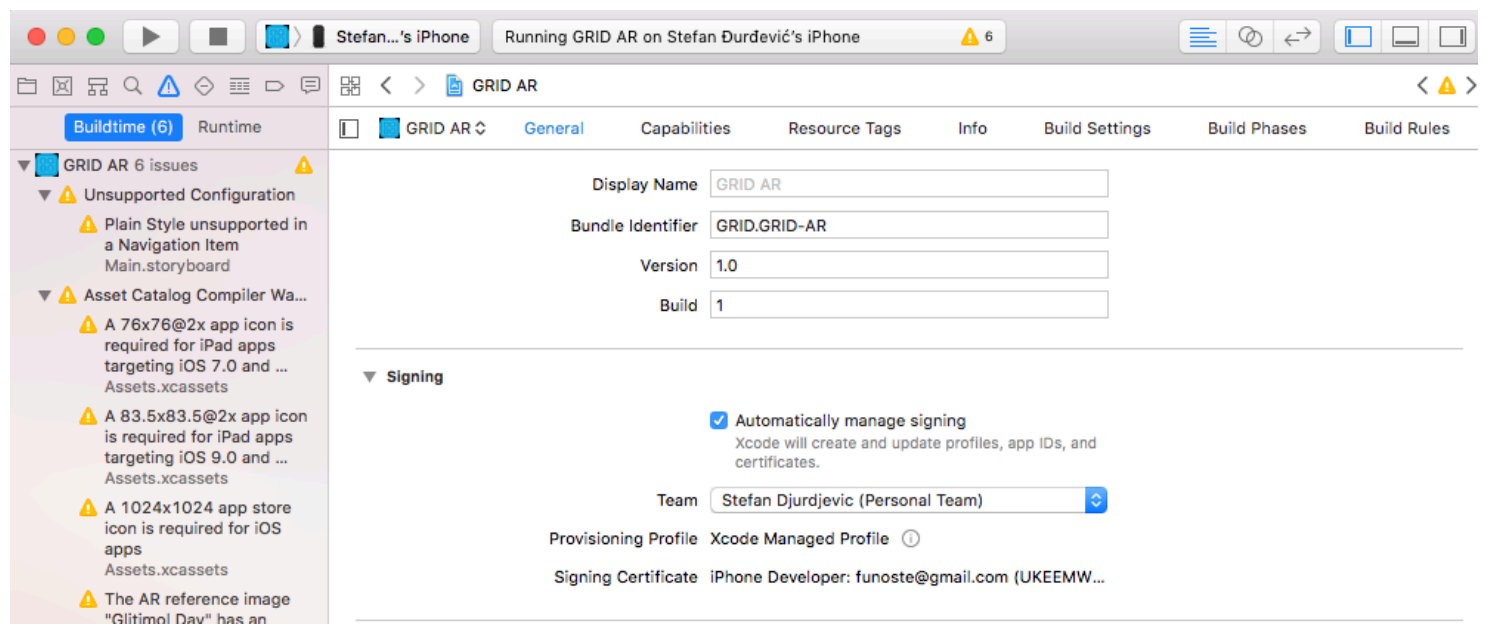

Figure 5: Building Smart Packaging Application on iPhone in Xcode

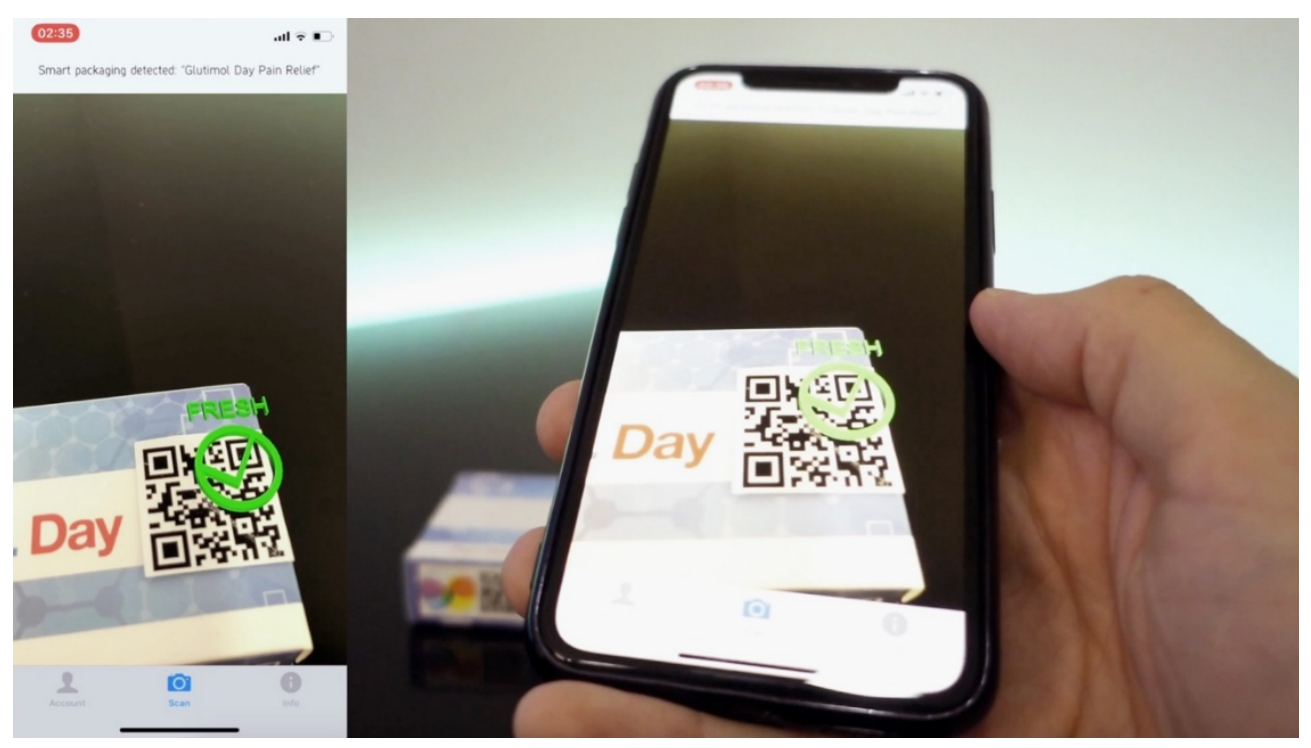

Figure 6: AR Smart Packaging App Demo 


\section{DISCUSSION}

The final application is a working AR application; it fully meets all the requirements for an AR application. As a result, the service was able to show the product state (freshness) depending on smart label state and packaging image target and to provide a variety of information in a very accurate and fast way. The application also has GPS working features to personalise information depending on the phones GPS location. GPS integration can help the application to recognise the Store and find the product price depending on location.

\section{CONCLUSION}

The AR concept of the smart packaging shows that it is possible to create an application for reading content and checking the product freshness in smart packaging using smart labels. Current technological advances ensure the implementation of such a control system. In the future, we expect the fall in prices of smart inks for printing smart labels and greater development of AR. Advances in powerful CPU, camera, accelerometer, GPS, and solid state compass are present in all mobile phones today, making them the best handheld platform for this AR system. However, their small display size is less than ideal for 3D user interfaces, but it is expected that in the future this system will be able to adapt and head mounted displays (HMD) and spatial displays.

\section{ACKNOWLEDGEMENTS}

This work was supported by the Serbian Ministry of Science and Technological Development, Grant No.:35027 "The development of software model for improvement of knowledge and production in graphic arts industry".

\section{REFERENCES}

[1] Azuma, R. T.: "A Survey Of Augmented Reality", Presence Teleoperators and Virtual Environments 6(4), 1997, 355-385. doi: 10.1162/pres.1997.6.4.355

[2] Camigniani, J., Furht, B., Anisetti, M., Ceravolo, P., Damiani E., Ivkovic. M.: “Augmented Reality Technologies, Systems and Applications." Multimedia Tools and Application, 51(1), 341 - 377, 2010. doi: 10.1007/s11042-010-0660-6

[3] Caudell, T., Mizell, D.: “Augmented Reality: An Application of Heads-Up Display Technology to Manual Manufacturing Process", Proceedings of Twenty-Fifth Hawaii International Conference on System Sciences, volume 2, (Kauai, HI, USA, 1992) 659 - 669. doi: 10.1109/HICSS.1992.183317

[4] Đurđević, S., Novaković, D., Zeljković, Ž., Kašiković, N.: "Thermochromic inks and augmented reality as part of novel smart packaging solutions", Proceedings of 2nd Internacional Printing Technologies Symposium Printistanbul, 2. (Printlstanbul, Istanbul: Marmara Üniversitesi, 2017), 153-159.

[5] Febech, B., Hellstrom, B., Henrysdotter, G., Hjulmand, M., Nilsson, J., Rudinger, L., Sipilainen, T., Solli, E., Svensson, K., Thorkelsson, A., Tuomaala, V.: “Active and intelligent food packaging: A Nordic report on the legislative aspects", (Nordic Council of Ministers, Copenhagen, 2000).

[6] Furht, B.: "Handbook of Augmented Reality", (Springer Publishing Company, New York, 2011).

[7] Hunger, K.: "Industrial Dyes: Chemistry, Properties, Applications", (WILEY-VCH Verlag GmbH \& Co. KGaA, Weinheim, 2003).

[8] Jung, K., Lee, S., Jeong, S., Choi, B.: "Virtual Tactical Map with Tangible Augmented Reality Interface", Proceedings of International Conference on Computer Science and Software Engineering, volume 2 (Wuhan, China, 2008), 1170-1173. doi: 10.1109/CSSE.2008.1305

[9] Packagingdigest, "Smart Packaging", Packagingdigest, URL: http://www.packagingdigest.com/smart-packaging_(last request: 2018-10-24).

[10] Platonov, J., Heibel, H., Meier, P., Grollmann, B.: "A mobile markerless AR system for maintenance and repair", Proceedings of IEEE/ACM International Symposium on Mixed and Augmented Reality, (ISMAR, Santa Barbard, CA, USA, 2006), 105-108.

[11] Reitmayr, G., Schmalstieg, D.: "Collaborative Augmented Reality for Outdoor Navigation and Information Browsing", Proceedings of the Second Symposium on Location Based Services and TeleCartography, (Vienna University of Technology, Austria, 2004), 53-62. 
[12] Sfxc, "SFXC | Special Effects and Coatings", Sfxc, URL: https://www.sfxc.co.uk/products/chameleonthermochromic-ink-trail-pack-for-paper-board-and-textiles (last request: 2018-03-24).

[13] Sielhorst, T., Obst, T., Burgkart, R., Riener, R., Navab, N.: “An Augmented Reality Delivery Simulator for Medical Training", International Workshop on Augmented Environments for Medical Imaging MICCAI Satellite Workshop, 2004.

[14] Siltechlimited, "Siltech limited smart inks", Siltechlimited, URL: http://siltechlimited.com/ (last request: 2018-03-23).

[15] Stančić, M., Kašiković, N., Novaković, D., Milošević, R., Grujić, D.: "Thermal Load Effect on Print Quality of Ink Jet Printined Textile Materials", Journal of Graphic Engineering and Design, 4 (2), 27-33, 2013.

[16] Tholsgard, G.: "3D rendering and interaction in an augmented reality mobile system", (UPPSALA University, Department of Information Technology, 2014), page 7.

[17] Van Krevelen, R., Poelman. R.: "A Survey of Augmented Reality Technologies, Applications and Limitations", The International Journal of Virtual Reality, 9(2), 1-20, 2010.

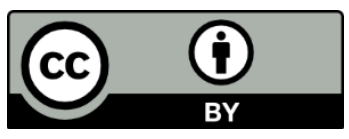

(C) 2018 Authors. Published by the University of Novi Sad, Faculty of Technical Sciences, Department of Graphic Engineering and Design. This article is an open access article distributed under the terms and conditions of the Creative Commons Attribution license 3.0 Serbia (http://creativecommons.org/licenses/by/3.0/rs/). 